\title{
Effect of Preoperative Ketamine and Magnesium Sulfate on Intra \& Postoperative Analgesia in Laparoscopic Cholecystectomy: A Comparative Randomized Controlled Study
}

\author{
Nagarjuna Thakur ${ }^{1}$, Ravikanth Pula ${ }^{2}$, Ravichandra Raya ${ }^{3}$ \\ ${ }^{1,2}$ ESIC Medical College, Sanath Nagar, Hyderabad, Telangana 500038, ${ }^{3}$ Global Hospital, 6-1-1040/1 to 4, Lakdikapul, Hyderabad, Telangana 500004.
}

\section{Abstract}

Background: The pain management using N-methyl-D-aspartate antagonist drugs like ketamine and magnesium sulfate during intraoperative, and postoperative period plays a major role by reducing the opioid usage. A comparative randomized controlled study was assessed to identify the best analgesic drug among two different N-methyl-D-aspartate antagonists in laparoscopic cholecystectomy patients. Subjects and Methods: Enrolled patients were equally divided into three groups 20 for each group, First group were administered with normal saline bolus, group 2 with ketamine and group 3 with magnesium sulfate as preoperative analgesic. Results: The results showed that ketamine group consumed $53.66 \%$ less fentanyl over the controls and $14.64 \%$ in magnesium sulfate. Cumulative morphine consumption was $10.2 \pm 2 \mathrm{mg}$ in controls, $7.2 \pm 2 \mathrm{mg}$ in ketamine and $6.5 \pm 2 \mathrm{mg}$ in magnesium groups were resulted a less consumption of postoperative morphine. There are no symptoms like nausea, vomiting, and pruritus was observed. Thus Ketamine and magnesium both were found to be effective in reducing introperative and post operative analgesic consumption. Conclusion: Therefore, it could be concluded that the preoperative usage of ketamine and magnesium sulfate was safe and reduces requirement of opioid for the major surgeries.

Keywords: Analgesics, Ketamine, Magnesium sulfate, Postoperative pain, Fentanyl, Morphine.

Corresponding Author: Dr. Ravikanth Pula, Assistant professor, Dept of Anesthesiology, ESIC Medical College, Sanath Nagar, Hyderabad, Telangana 500038

Received: November 2019

Accepted: November 2019

\section{Introduction}

Postoperative pain is a considerable problem for patients which last up to five days. It remains a big challenge for anesthesiologists and acute pain medicine specialists to keep the patient stable under opioid analgesic infusion. In spite of the increasing practice of advanced medical techniques such as multimodal analgesic treatments, regional anesthesia and sustained infusion of postoperative analgics, the number of patients still suffering from chronic postoperative pain is sizable. ${ }^{[1]}$ Pain retention or perpetuation is usually the aftereffect of sensitization of central and peripheral neurons in the case of surgery. Therefore a deep analytical understanding of preventive analgesia in relation to the systemic neurons is essential for sustained attenuation of pain processing. Regular investigative and comparative studies are necessary to fully elucidate the mechanisms causing neural sensitization pathways. One such attempt has been made in the current investigation by understanding the comparative effect of ketamine and magnesium sulfate in combination with the regularanesthesia.

Literature says that any major surgeries suppress the immunity of the person in invivo and invitro which may lead to the person's immunodepression after surgery. ${ }^{[2]}$
Inadequate pain control results in increased mortality of the postoperative patients. ${ }^{[3]}$ So, it is important to control pain after surgery needs to be quantified and treat effectively by preventive analgesia. ${ }^{[4]} \mathrm{N}$-methyl D-aspartate (NMDA) receptors will maintain and induce the central sensitization of pain which can be prevented by administration of NMDA receptor antagonists. ${ }^{[5]}$ As of now no NMDA receptor antagonists are available in the market for clinical use. However, few of the compounds that have significant NMDA receptor blocking properties are approved to administer in human for several clinical implications. Among the approved NMDA receptors ketamine and magnesium sulfate are the key modulators as adjuvant drugs in chronic pain management and analgesia prevention at lower doses. ${ }^{[6]}$ Ketamine is phencyclidine derivative that possess the properties of anti-allodynia, anti-tolerance, and antihyperalgesia. ${ }^{[7]}$ Many clinical conditions like chemotherapy, major surgeries, pathologic pain and chronic diseases involve neuropathic pain and central sensitization. For such conditions ketamine act as best supportive analgesic drug along with opioids. For NMDA receptors ketamine acts as antagonist, two enantiomers of ketamine will be released from the cyclohexane ring of $\mathrm{C} 2$ atom that binds to the phencyclidinic site on postsynaptic channels. ${ }^{[8]}$

Severe pain status an increment doses of the NMDA 
receptors controls central sensitization and hyperalgesia, in such case ketamine as adjuvant therapy stops nociceptve transmission to the brain. ${ }^{[9]}$ Apart from this ketamine also manages the blood pressure, spontaneous breathing and laryngeal reflexes. ${ }^{[10]}$

Magnesium sulfate is a versatile drug that uses majorly for preeclampsia patients to prevent seizures and also used for the patients who are suffering from arrhythmia, and asthma. $^{[11]}$ Usually during surgery magnesium sulfate regimen will administer $30-50 \mathrm{mg} / \mathrm{kg}$ initially and then fallows a maintenance dose of $6-20 \mathrm{mg} / \mathrm{kg} / \mathrm{h}$ till completion of surgery. ${ }^{[12]}$ Many authors in their research said that intraoperative magnesium usage reduced the necessity of anesthetics, muscle relaxants and opioid consumption in first 24hrs. ${ }^{[13]}$ Similar to ketamine, magnesium also blocks NMDA receptors by inhibiting the calcium ions, and leads to nociceptive action and central sensitization. ${ }^{[14]}$ The main aim of the present study is to use the lower dose of Ketamine (analgesic dose) or magnesium preoperatively as pre-emptive analgesics, and assessment of the intra operative and postoperative analgesic requirement in patients undergoing laparoscopic cholecystectomy (using Visual Analogue Score, VAS). Also to check the comparisons between efficacies of Ketamine and magnesium as pre- emptive analgesics, ifany.

\section{Subjects and Methods}

\section{Ethics Approval}

This study of ketamine and magnesium sulfate on intra and postoperative analgesia was conducted with the approval of the institutional medical ethics committee of ESIC Medical College, Hyderabad.

\section{Study Design}

The present randomized double blind controlled study was conducted between 2008 and 2009 for 15 months in patients undergoing elective laparoscopic cholecystectomy at our Global Hospital. Sixty enrolled patients were selected between the age group of 20-65 yrs of both the sexes. Before enrolling the patients for study, written informed consent was taken from all the patients.

\section{Inclusion criteria}

- ASA grade I and II patients scheduled for elective laparoscopic cholecystectomy

- The patients having the age of 20 and above were chosen for study.

\section{Exclusion criteria for patients}

- Patients who were having a history of cardiac arrhythmias, psychiatric disorders, neuromuscular disorders, pulmonary, Bronchial asthma and hepatic or renaldysfunction

- Patients with obesity, acid peptic disorders, and high serum magnesiumlevels

- Few of the excluded patients with preoperative use of opioids, beta blockers and calcium channelblockers

- Patients those are allergic tomorphine

Study Design

All the patients were observed for preoperative assessment by checking the cardiovascular symptoms, any prior medication, allergic to any specific drugs and performed general systemic examination. All the patients were starved for overnight prior to the operation. The patients who meet the eligibility criteria were randomly divided into three groups with 20 patients per each group.

Group I: placebo group received intravenous normal saline Group II: Ketamine group received $0.5 \mathrm{mg} / \mathrm{kg}$ intravenously Group III: Magnesium sulfate group received $20 \mathrm{mg} / \mathrm{kg}$ intravenously

The drugs ketamine and magnesium sulfate were diluted in $20 \mathrm{ml}$ of normal saline and slowly infused preoperatively to the study group patients for a period of 10 minutes. All the study patients were instructed about the use of visual analogue scale for pain. A standard horizontal $10 \mathrm{~mm}$ linear visual analogue scale was used to assess pain at rest and on coughing $(0=$ no pain at all. $10=$ worst pain imaginable $)$. All the patients were reviewed with haemogram, CBP, blood sugar \& urea, serum electrolytes, magnesium \& creatinine, chest $\mathrm{X}$-ray, andelectrocardiogram.

\section{Treatment and Evaluation}

In the operation theatre all the patients were evaluated with pulse rate $(\mathrm{PR}), \mathrm{BP}$, respiratory rate (RR), oxygen saturation (SPO2), continuous ECG. An intravenous access was secured on each patient with an 18 gauge intravenous catheter. Ten minutes before administering the anesthesia, study drug was given to the respective patients. All the patients were premedicated with intravenous injection of $4 \mathrm{mg}$ ondansetron. After preoxygenating the patient with $100 \%$ oxygen for 3 minutes, general anesthesia was induced with Inj. propofol $2 \mathrm{mg} / \mathrm{kg}$, and Inj. fentanyl $2 \mu \mathrm{g} / \mathrm{Kg}$ as analgesic. Intubation was facilitated with Inj. vecuronium $0.1 \mathrm{mg} / \mathrm{kg}$ and the patient's trachea was intubated with appropriate sized endotracheal tube. Anesthesia was maintained with air - oxygen mixture in a ratio of 50:50 with isoflurane. Vecuronium was given whenever required. During operation, heart rate, blood pressure, oxygen saturation and ETCO2, were monitored continuously and recorded every 15 minutes. Intra operative pain was determined by increase of mean arterial pressure and heart rate more than $20 \%$ from base line values and was managed with $0.5-1 \mu \mathrm{g} / \mathrm{kg}$ of fentanyl, as boluses till heart rate and mean arterial pressure returned to baseline.

Since administration of magnesium may increase the level of neuromuscular blockade, muscle relaxation was monitored continuously with a peripheral nerve stimulator. Total amount of fentanyl required was recorded. At the end of surgery, neuromuscular paralysis was reversed using neostigmine $0.05 \mathrm{mg} / \mathrm{kg}$ and glycopyrrolate $8 \square \mathrm{g} / \mathrm{kg}$. After full recovery, patients were extubated and shifted to post anesthesia care unit. The patients pulse rate, blood pressure and visual analogue score at rest and on cough were monitored continuously and recorded for next two hours and then shifted to ward as appropriate.

\section{Postoperative Pain management}

After completion of surgery patient was given with suppository diclofenac sodium $100 \mathrm{mg}$ fallowed by $100 \mathrm{mg}$ orally after $12 \mathrm{hrs}$. For all the patients were prescribed to take Tab. Paracetamol 1g Q.I.D orally. For the patients who were 
having VAS five and above were administered intramuscularly with 50-100 micrograms/kg Inj. morphine sulphate. Postoperative observation with blood pressure (NIBP), oxygen saturation, visual analogue scores at rest and on coughing (VAS) were recorded at $0,1,4,6 \& 24$ hours. Requirement of morphine sulfate was also recorder and no other sedative and analgesics were used.

\section{Statistical analysis}

All the different parameters of the study patients were analyzed using ANOVA test by using windostat statistical program version 9.1. Kruskal-Wallis one-way analysis of variance was used to calculate the demographic trend, heart rate, blood pressure, serum magnesium levels, oxygen saturation, respiratory rate, end tidal $\mathrm{CO} 2$, additional fentanyl requirement, visual analogue scores at rest and on cough, morphine consumption for first $24 \mathrm{hrs}$. If statistically significant result obtained, Dunnett's test was performed to determine considerable difference between groups. In addition, t- test was also performed between placeboketamine, and placebo-magnesium groups to confirm Dunnett test results. 'p' value $<0.05$ was considered as statistically significant and the results were expressed as mean \pm SEM and median.

\section{Results}

Surgery time for the patients was ranged from 78 to 89.2 minutes and all the surgeries were performed by same surgeon and surgical staff. Demographic data of gender, age, weight of the patient and surgery duration was tabulated in table 1 , in which no statistical significance was observed in all the three groups. This indicates that the different age groups from 37 to 46 and difference in weights in the study were not faced any complications with operation duration as well as with the ketamine and magnesium sulfate when used as analgesia.

Table 1: Demographic characteristics of patients, and duration of operation among the groups. Values represented as Mean \pm SEM.

\begin{tabular}{|l|l|l|l|}
\hline & Group 1 & Group 2 & Group 3 \\
\hline Gender (M/F) & $\mathbf{9 / 1 1}$ & $\mathbf{1 3 / 7}$ & $\mathbf{1 2 / 8}$ \\
\hline Age(yrs) & $45.8 \pm 15.9$ & $43.0 \pm 10.0$ & $37.6 \pm 11.0$ \\
\hline Weight (kg) & $62.3 \pm 9.0$ & $63.5 \pm 8.51$ & $58.9 \pm 8.0$ \\
\hline $\begin{array}{l}\text { Duration of operation } \\
\text { (min.) }\end{array}$ & $78.0 \pm 18.5$ & $81.7 \pm 23.0$ & $89.2 \pm 18.5$ \\
\hline
\end{tabular}

All the three groups' preoperative serum magnesium levels were resulted in normal limits. In figure 1 it is observed that preoperative heart rate was equal in all the groups where as there was a gradual increase all the different time intervals. It is resulted that the mean and standard error ofmeanforintraoperativeheartrateincontrolgroupwashigherat 4 5and120minuteswithp $<0.05 \quad(0.023,0.003$ respectively $)$ when compared to the other two ketamine and magnesium sulfate groups [Table 2]. At 30 minutes time point heart rate of placebo and magnesium sulfate groups were almost same with 85.5 and 84.3 but no significance was seen.
Table 2: Mean and SEM for preoperative and intraoperative heart rate. (* Indicates statistical significance).

\begin{tabular}{|l|l|l|l|l|}
\hline & Group 1 & Group 2 & Group 3 & p - Value \\
\hline Preoperative & $80.0 \pm 9.3$ & $80.3 \pm 5.6$ & $80.4 \pm 11.8$ & 0.9 \\
\hline $15 \mathrm{~min}$ & $79.6 \pm 16.0$ & $75.5 \pm 11.2$ & $77.7 \pm 13.1$ & 0.6 \\
\hline $30 \mathrm{~min}$ & $85.5 \pm 15.1$ & $79.9 \pm 9.4$ & $84.3 \pm 11.1$ & 0.3 \\
\hline $45 \mathrm{~min}$ & $88.3 \pm 12.1$ & $80.5 \pm 9.8$ & $80.2 \pm 8.3$ & $0.023^{*}$ \\
\hline $60 \mathrm{~min}$ & $86.5 \pm 13.4$ & $81.1 \pm 6.2$ & $82.1 \pm 12.4$ & 0.2 \\
\hline $75 \mathrm{~min}$ & $85.2 \pm 9.6$ & $81.3 \pm 7.6$ & $82.6 \pm 12.9$ & 0.5 \\
\hline $90 \mathrm{~min}$ & $86.1 \pm 9.7$ & $82.4 \pm 8.9$ & $82.1 \pm 5.6$ & 0.5 \\
\hline $105 \mathrm{~min}$ & $88.7 \pm 11.7$ & $84.5 \pm 6.3$ & $81.4 \pm 6.6$ & 0.3 \\
\hline $120 \mathrm{~min}$ & 90.0 & $80.0 \pm 1.6$ & $79.0 \pm 1.0$ & $0.003^{*}$ \\
\hline \multicolumn{5}{|c|}{} \\
\hline \multicolumn{5}{|l}{}
\end{tabular}

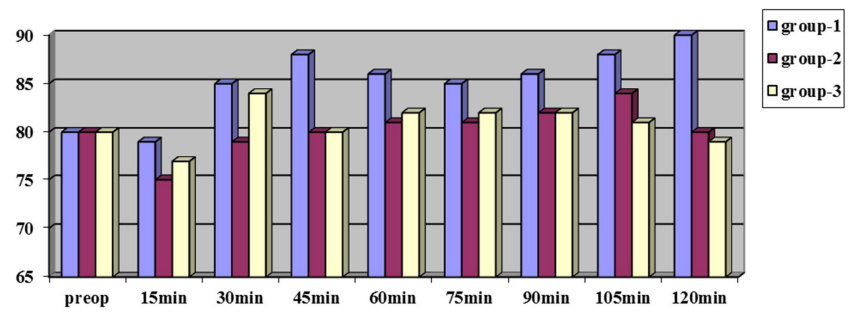

Figure 1: Graphical representation of mean heart rate in all the three experimental groups.

The resulted systolic blood pressure was observed during preoperative and intraoperative at every 15 minutes intervals and it was statistically significant at 45, 60 and 90 minutes in placebo group [Table 3]. It is showed that the $p$ value is less than 0.05 i.e. $0.038^{*}, 0.048^{*}, 0.003^{*}$ at 45,60 , and $90 \mathrm{~min}$. respectively. Considerable major systolic blood pressure was not observed at all the intervals during operation in all the three groups [Figure 2].

Table 3: Mean and SEM for preoperative and intraoperative systolic blood pressure. (* Indicates statisticalsignificance).

\begin{tabular}{|l|l|l|l|l|}
\hline & Group 1 & Group 2 & Group 3 & p - Value \\
\hline Preoperative & $122.2 \pm 10.5$ & $124.8 \pm 8.2$ & $121.9 \pm 8.7$ & 0.5 \\
\hline $\begin{array}{l}15 \text { min } \\
\text { After }\end{array}$ & $112.2 \pm 12.5$ & $105.7 \pm 8.2$ & $111.7 \pm 13.0$ & 0.1 \\
\hline $30 \mathrm{~min}$ & $130.6 \pm 14.3$ & $123.5 \pm 11.2$ & $125.9 \pm 15.4$ & 0.2 \\
\hline 45 min & $131.7 \pm 9.2$ & $123.1 \pm 11.2$ & $128.0 \pm 10.6$ & $0.038^{*}$ \\
\hline 60 min & $130.9 \pm 11.2$ & $122.3 \pm 10.9$ & $123.6 \pm 11.4$ & $0.048^{*}$ \\
\hline $75 \mathrm{~min}$ & $128.0 \pm 7.3$ & $123.0 \pm 7.5$ & $128.8 \pm 9.0$ & 0.1 \\
\hline $90 \mathrm{~min}$ & $132.9 \pm 5.4$ & $121.1 \pm 8.8$ & $132.6 \pm 8.1$ & $0.003^{*}$ \\
\hline $105 \mathrm{~min}$ & $131.0 \pm 1.4$ & $123.0 \pm 12.2$ & $127.2 \pm 8.8$ & 0.6 \\
\hline $120 \mathrm{~min}$ & $130.0 \pm 1.4$ & 120.0 & 118.000 & 0.724 \\
& & \pm 10.583 & \pm 14.142 & \\
\hline
\end{tabular}

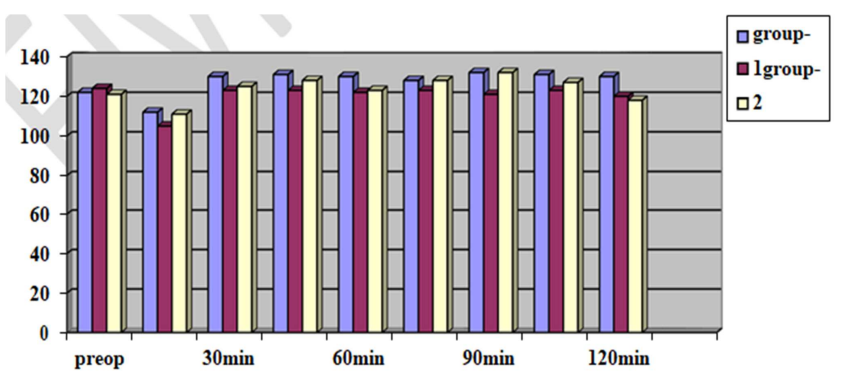

Figure 2: Graphical representation of mean systolic blood pressure in all the three experimental groups.

Similarly as heart rate and systolic blood pressure, the 
diastolic blood pressure was also observed preoperatively and intraoperatively. The significance difference of 0.046 was observed at 105 minutes in placebo group of the patients when compared to ketamine and magnesium sulfate groups [Table 4]. At 120 minutes of intraoperative period, the diastolic blood pressure seems to be same with 89 and 89.5 in control and magnesium sulfate groups but no statistical significance was observed [Figure 3].

Table 4: Mean and SEM for preoperative and intraoperative diastolic blood pressure. (* Indicates statisticalsignificance).

\begin{tabular}{|l|l|l|l|l|}
\hline & Group 1 & Group 2 & Group 3 & p - Value \\
\hline Preoperative & $76.1 \pm 7.3$ & $77.5 \pm 5.0$ & $73.6 \pm 5.7$ & 0.1 \\
\hline $\begin{array}{l}15 \text { min after } \\
\text { intubation }\end{array}$ & $70.2 \pm 10.5$ & $66.8 \pm 6.2$ & $69.0 \pm 9.7$ & 0.4 \\
\hline $30 \mathrm{~min}$ & $80.4 \pm 10.0$ & $76.2 \pm 8.8$ & $76.2 \pm 9.3$ & 0.2 \\
\hline $45 \mathrm{~min}$ & $79.1 \pm 10.8$ & $75.2 \pm 8.7$ & $77.3 \pm 9.1$ & 0.4 \\
\hline $60 \mathrm{~min}$ & $77.1 \pm 9.1$ & $77.6 \pm 10.2$ & $78.0 \pm 10.7$ & 0.9 \\
\hline $75 \mathrm{~min}$ & $79.3 \pm 8.8$ & $77.4 \pm 5.8$ & $77.1 \pm 8.1$ & 0.7 \\
\hline $90 \mathrm{~min}$ & $79.3 \pm 8.0$ & $76.7 \pm 10.0$ & $75.3 \pm 11.0$ & 0.6 \\
\hline $105 \mathrm{~min}$ & $87.0 \pm 4.2$ & $74.4 \pm 4.5$ & $79.0 \pm 5.8$ & $0.046^{*}$ \\
\hline $120 \mathrm{~min}$ & 89.0 & $80.6 \pm 11.3$ & $89.5 \pm 0.7$ & 0.5 \\
\hline
\end{tabular}

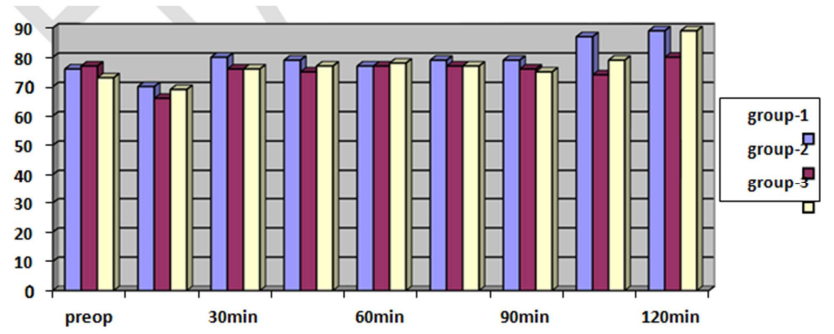

Figure 3: Graphical representation of mean diastolic blood pressure in all the three experimental groups.

During the treatment procedure fentanyl was given as analgesia as well as bolus at the time of surgery. When calculated the additional usage of fentanyl in three groups, it is observed that mean introperative usage of fentanyl was more i.e. $51.2 \mathrm{mcg}$ when compared to the ketamine and magnesium sulfate [Table 5]. In group 2 the fentanyl consumption was $23.7 \mathrm{mcg}$ which is $53.66 \%$ lesser than control and in group 3 consumption was $43.7 \mathrm{mcg}$ that is $14.6 \%$ lesser when compared to the controlgroups.

Table 5: Mean usage of introperative fentanyl.

\begin{tabular}{|l|l|}
\hline Cateogory & Fentanyl Usage \\
\hline Group 1 (Control) & $51.2 \pm 29.7$ \\
\hline Group 2 (Ketamine) & $23.7 \pm 18.9$ \\
\hline Group 3 (Magnesium Sulfate) & $43.7 \pm 24.1$ \\
\hline
\end{tabular}

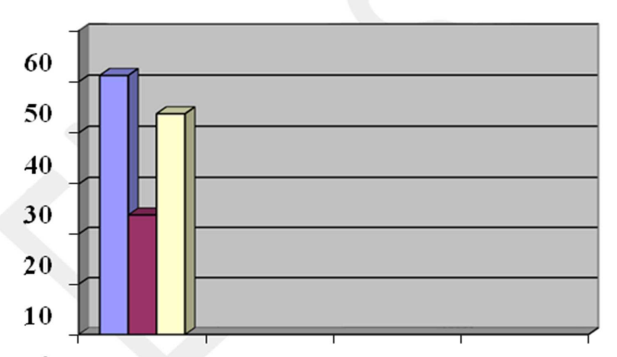

$\square$ group-1

$\square$ group-2

$\square$ group-3

0

Additional fentanyl (mic)

Figure 4: Graphical representation of intraoperative additional fentanyl use in all the different groups.
Postoperative heart rate was checked from $0 \mathrm{hr}$ to $24 \mathrm{hrs}$ for all the patients in three groups. It was resulted that there is no significant difference in the mean post operative heart rate between controls, ketamine and magnesium sulfate groups [Figure 5]. Heart rate in all the three groups was decreased gradually from 90 to 70 from 0 hrs to $24 \mathrm{hrs}$ respectively [Table 6]. This indicates that the heart rate with the ketamine and magnesium sulfate analgesia were not influenced the heart rate of the postoperative patients.

\section{Table 6: Mean and SEM for postoperative heart rate.}

\begin{tabular}{|l|l|l|l|l|}
\hline & Group 1 & Group 2 & Group 3 & p - value \\
\hline $0 \mathrm{hr}$ & $90.2 \pm 10.8$ & $87.5 \pm 7.5$ & $90.5 \pm 9.6$ & 0.545 \\
\hline $1 \mathrm{hr}$ & $84.3 \pm 9.2$ & $83.1 \pm 7.4$ & $87.9 \pm 8.5$ & 0.188 \\
\hline $4 \mathrm{hr}$ & $82.1 \pm 8.4$ & $85.2 \pm 8.7$ & $82.6 \pm 10.7$ & 0.529 \\
\hline $6 \mathrm{hr}$ & $78.3 \pm 6.9$ & $78.5 \pm 7.2$ & $75.0 \pm 6.4$ & 0.208 \\
\hline $24 \mathrm{hr}$ & $76.5 \pm 7.7$ & $74.4 \pm 7.5$ & $74.0 \pm 6.3$ & 0.509 \\
\hline
\end{tabular}

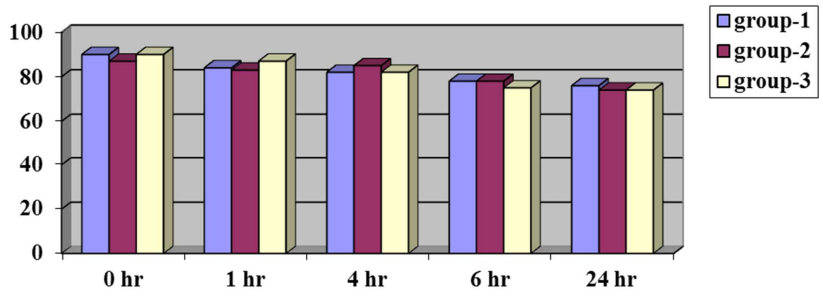

Figure 5: Postoperative heart rate till $24 \mathrm{hrs}$ in three groups.

Postoperative systolic blood pressure was calculated from 0$24 \mathrm{hrs}$ in all the three group patients. It is observed at 4thand 6thhrs in control groups was significantly higher when compared to the other two groups [Table 7]. Both the analgesia groups were not shown any significant effect on systolic blood pressure [Figure 6].

Table 7: Mean and SEM for post operative systolic blood pressure

\begin{tabular}{|l|l|l|l|l|}
\hline & Group 1 & Group 2 & Group 3 & p - value \\
\hline $0 \mathrm{hr}$ & $130.9 \pm 11.2$ & $126.3 \pm 7.0$ & $127.7 \pm 7.1$ & 0.239 \\
\hline $1 \mathrm{hr}$ & $129.3 \pm 8.9$ & $129.8 \pm 9.4$ & $128.6 \pm 12.7$ & 0.936 \\
\hline $4 \mathrm{hr}$ & $131.0 \pm 8.3$ & $128.9 \pm 10.7$ & $122.4 \pm 11.2$ & $0.027^{*}$ \\
\hline $6 \mathrm{hr}$ & $132.0 \pm 8.3$ & $123.2 \pm 7.3$ & $122.3 \pm 9.4$ & $0.001^{*} *$ \\
\hline $24 \mathrm{hr}$ & $120.5 \pm 5.4$ & $121.1 \pm 6.9$ & $119.7 \pm 4.8$ & 0.760 \\
\hline
\end{tabular}

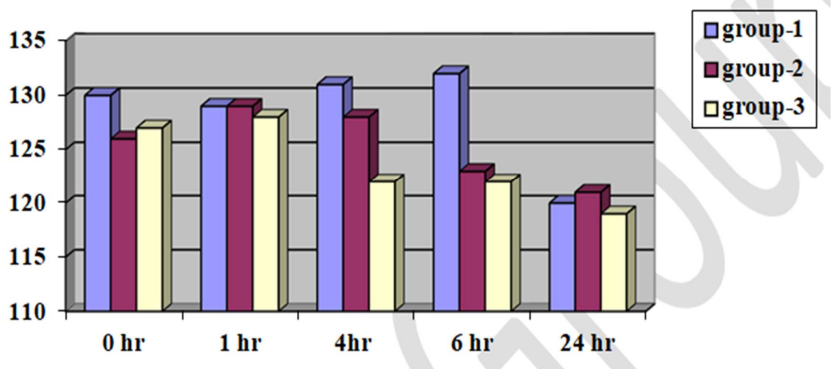

Figure 6: Graphical representation of post operative systolic blood pressure.

The resultant postoperative diastolic blood pressure was significantly high (81.3) at 6thhour in control group when compared to ketamine and magnesium sulfate groups [Table 8]. The diastolic blood pressure was low in control groups at 0 and 1 sthour if compared to other two groups but there was a gradual increase in the rate at 4thand 6thhrs. 
Though there was a decrease to 76 at 24thhour still higher in diastolic blood pressure over the other two groups [Figure 7].

Table 8: Mean and SEM for post operative diastolic blood pressure

\begin{tabular}{|l|l|l|l|l|}
\hline & Group-1 & Group-2 & Group-3 & $\begin{array}{l}\text { p- } \\
\text { value }\end{array}$ \\
\hline $0 \mathrm{hr}$ & $77.4 \pm 8.8$ & $78.950 \pm 6.901$ & $75.150 \pm 6.777$ & 0.287 \\
\hline $1 \mathrm{hr}$ & $77.4 \pm 7.5$ & $78.550 \pm 6.724$ & $79.550 \pm 10.526$ & 0.715 \\
\hline $4 \mathrm{hr}$ & $80.5 \pm 7.6$ & $78.000 \pm 9.581$ & $75.150 \pm 8.087$ & 0.146 \\
\hline $6 \mathrm{hr}$ & $81.3 \pm 5.7$ & $75.850 \pm 7.095$ & $73.350 \pm 4.987$ & $0.000^{* *}$ \\
\hline $24 \mathrm{hr}$ & $76.5 \pm 5.6$ & $74.700 \pm 6.868$ & $74.950 \pm 6.039$ & 0.773 \\
\hline $\mathbf{8}$ \\
$\mathbf{8 0}$ \\
$\mathbf{8 0}$ \\
$\mathbf{7 6}$ \\
$\mathbf{7 4}$ \\
$\mathbf{7 2}$ \\
$\mathbf{7 0}$ \\
$\mathbf{6 8}$
\end{tabular}

Figure 7: Graphical representation of post operative diastolic blood pressure.

A visual analogue score was measured for all the patients to assess the intensity of the pain after surgery from 0 to $24 \mathrm{hrs}$ at rest. It is observed that three of group 1 and group 3 patients underwent slight pain at first hour where as four of group 2 patients underwent pain 4thhour [Figure 8]. But there was no observed statistical significant pain in any group at resting period [Table 9].

Table 9: Mean and SEM for visual analogue score at rest.
\begin{tabular}{|l|l|l|l|l|}
\hline & Group-1 & Group-2 & Group-3 & $\begin{array}{l}\text { p - } \\
\text { value }\end{array}$ \\
\hline $0 \mathrm{hr}$ & $1.400 \pm 1.984$ & $0.850 \pm 1.899$ & $0.850 \pm 1.461$ & 0.539 \\
\hline $1 \mathrm{hr}$ & $3.250 \pm 1.410$ & $2.700 \pm 1.174$ & $3.300 \pm 1.261$ & 0.269 \\
\hline $4 \mathrm{hr}$ & $2.300 \pm 1.342$ & $3.300 \pm 1.838$ & $2.250 \pm 1.410$ & 0.061 \\
\hline $6 \mathrm{hr}$ & $2.100 \pm 0.968$ & $1.400 \pm 0.940$ & $2.000 \pm 1.376$ & 0.108 \\
\hline $\begin{array}{l}24 \\
\mathrm{hr}\end{array}$ & $0.200 \pm 0.410$ & $0.100 \pm 0.308$ & $0.250 \pm 0.444$ & 0.472 \\
\hline
\end{tabular}
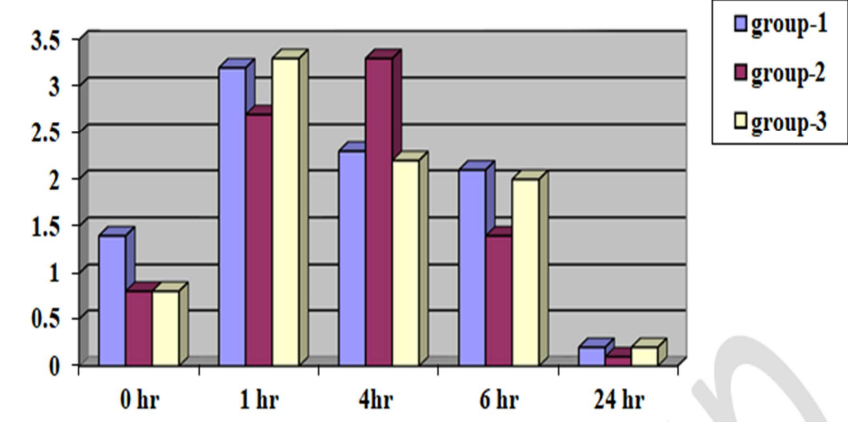

Figure 8: Graphical representation of visual analogue score at rest.

Similarly VAS at cough was also assessed in all groups from 0 to $24 \mathrm{hrs}$. The resultant score was high at 4thhour in ketamine group which is statistically significant when compare to placebo and magnesium sulfate group [Table 10]. There was also observed increment in pain at cough in the first hour of magnesium sulfate group, still there is no statistical significance [Figure 9].
Table 10: Mean and SEM for Visual analogue score on cough.

\begin{tabular}{|c|c|c|c|c|}
\hline & Group-1 & Group-2 & Group-3 & $p$-value \\
\hline $0 \mathrm{hr}$ & $\begin{array}{ll}2.750 & \pm \\
2.989 & \end{array}$ & $\begin{array}{ll}1.650 & \pm \\
2.300\end{array}$ & $\begin{array}{ll}2.300 & \pm \\
1.922\end{array}$ & 0.366 \\
\hline $1 \mathrm{hr}$ & $\begin{array}{l}5.700 \\
1.720\end{array}$ & $\begin{array}{ll}4.950 & \pm \\
1.761 & \end{array}$ & $\begin{array}{ll}6.150 & \pm \\
1.899 & \end{array}$ & 0.111 \\
\hline $4 \mathrm{hr}$ & $\begin{array}{l}4.000 \\
1.777\end{array}$ & $\begin{array}{ll}5.400 & \pm \\
2.210\end{array}$ & $\begin{array}{ll}3.750 & \pm \\
1.916\end{array}$ & $0.023^{*}$ \\
\hline $6 \mathrm{hr}$ & $\begin{array}{l}3.600 \\
1.635\end{array}$ & $\begin{array}{l}3.400 \\
1.569\end{array}$ & $\begin{array}{l}3.450 \\
1.849\end{array}$ & 0.927 \\
\hline $24 \mathrm{hr}$ & $\begin{array}{l}1.050 \\
0.945\end{array}$ & $\begin{array}{l}0.650 \\
0.745\end{array}$ & $\begin{array}{ll}0.950 & \pm \\
0.887\end{array}$ & 0.320 \\
\hline
\end{tabular}

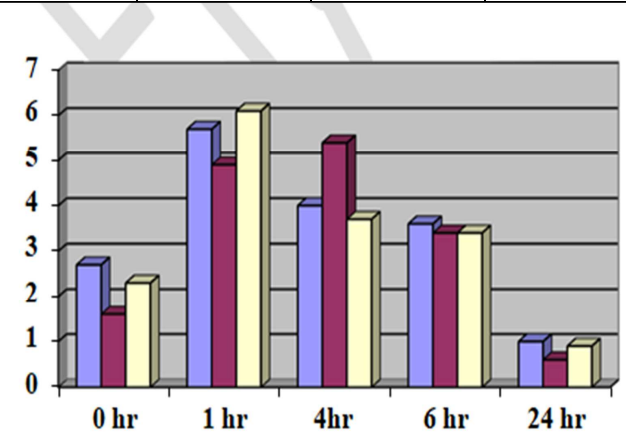

口group-1

पgroup-2

口group-3

Figure 9: Graphical representation of postoperative visual analogue score at cough.

Postoperative morphine requirement as a pain medicine was observed in all the three groups. It was seen in the graph that morphine consumption in ketamine group used less until 4thpostoperative hours. Whereas no significant consumption was observed in placebo and magnesium groups. Within the postoperative $24 \mathrm{hrs}$ morphine requirement was less in magnesium group then fallows ketamine group and highest consumption was observed in placebo group [Table 11, Figure 10].

Table 11: Mean and SEM for Morphine requirement in the postoperative period

postoperative period
\begin{tabular}{|l|l|l|l|l|}
\hline & Group-1 & Group-2 & Group-3 & $\begin{array}{l}\text { p - } \\
\text { value }\end{array}$ \\
\hline $0 \mathrm{hr}$ & $0.975 \pm 1.773$ & $0.225 \pm 1.006$ & $0.600 \pm 1.492$ & 0.275 \\
\hline $1 \mathrm{hr}$ & $3.150 \pm 2.001$ & $2.025 \pm 2.137$ & $3.375 \pm 2.058$ & 0.095 \\
\hline $4 \mathrm{hr}$ & $1.350 \pm 1.941$ & $2.400 \pm 2.251$ & $1.125 \pm 1.999$ & 0.124 \\
\hline $6 \mathrm{hr}$ & $1.425 \pm 2.034$ & $0.675 \pm 1.649$ & $0.600 \pm 1.492$ & 0.261 \\
\hline $\begin{array}{l}24 \\
\mathrm{hr}\end{array}$ & $3.525 \pm 1.634$ & $1.875 \pm 2.170$ & $0.825 \pm 1.719$ & $0.000^{* *}$ \\
\hline
\end{tabular}

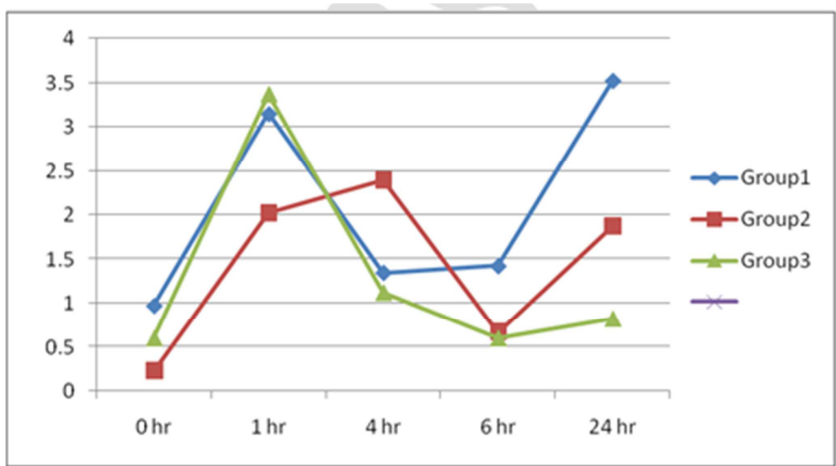

Figure 10: Comparison of total morphine requirement in three groups. 
Cumulative morphine consumption was less in treatment groups i.e. ketamine and magnesium. Ketamine group consumption was $30 \%$ less where as $36 \%$ less in magnesium group when compared to the placebo group [Table 12, Figure 11].

Table 12: Mean and SEM of cumulative morphine consumption
in three groups.
\begin{tabular}{|l|l|}
\hline Cateogory & Morphine Usage \\
\hline Group -1 & $10.2 \pm 2.5$ \\
\hline Group-2 & $7.2 \pm 2.0$ \\
\hline Group-3 & $6.5 \pm 2.8$ \\
\hline
\end{tabular}

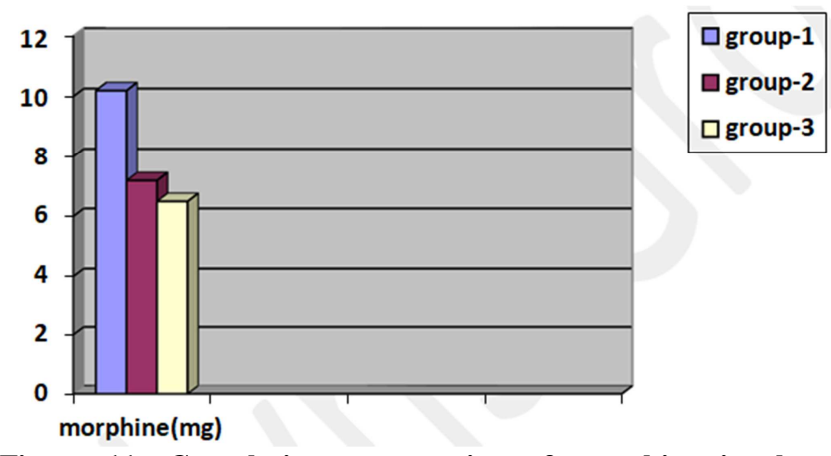

Figure 11: Cumulative consumption of morphine in three groups.

Intraoperative and postoperative side effects were observed in all the three groups. There were no significant symptoms observed in all the three group except hallucination in three ketamine group patients [Table 13].

Table 13: Comparison of incidence of introperative and postoperative side effects.

\begin{tabular}{|l|l|l|l|}
\hline & Group 1 & Group 2 & Group 3 \\
\hline Delayed recovery & 0 & 0 & 0 \\
\hline Pruritus & 0 & 0 & 0 \\
\hline Urinary retention & 0 & 0 & 0 \\
\hline Hallucinations & 0 & 3 & 0 \\
\hline Nausea \& vomitings & 0 & 0 & 0 \\
\hline
\end{tabular}

\section{Discussion}

In the present study, we have observed the laparoscopic cholecystectomic patients intra and postoperative effect on usage of Preoperative ketamine and magnesium sulfate as analgesia by comparing with control groups. A major criterion of the study is to reduce the pain, opioid consumption, shorter recovery and fentanyl consumption without any side effects. Our results revealed that the usage of a bolus of ketamine $(0.5 \mathrm{mg} / \mathrm{kg})$ and magnesium $(20 \mathrm{mg} / \mathrm{kg})$ were more efficient in post operative pain management, cumulative morphine consumption and reduced fentanyl consumption. It is also resulted that the systolic, diastolic blood pressure was maintained in a controlled manner at intra and postoperatively. In addition, visual analogue score was lower in both the treatment groups when compared to controlgroup.

A study conducted by Rodríguez-Rubio L, et al. ${ }^{[15]}$ administration perioperative magnesium sulfate as adjuvant, that reduced the need of opioids, propofol, and neuromuscular blockings. Similarly the present study used magnesium sulfate as adjuvant drug which showed the reduction in usage of fentanyl and cumulative morphine consumption. Another research by Dabbagh A, et al. in lower limb orthopedic surgery patients, when administered magnesium sulfate intravenously that showed suppression of postoperative pain and led to less usage of morphine for first 24 hrs. ${ }^{[16]}$ In support to Dabbagh A, et al. study our clinical trial also yielded the similar results with $3.5 \mathrm{mg} / \mathrm{kg}$ of morphine in placebo group at $24^{\text {th }}$ hour whereas 1.8 and 0.8 $\mathrm{mg} / \mathrm{kg}$ in ketamine and magnesium groups.

Lower dose of intraoperative and postoperative ketamine usage in major abdominal surgery improved postoperative analgesia, incidents of nausea and decreased in morphine consumption. ${ }^{[17]}$ The present case of lower ketamine dose i.e. $0.5 \mathrm{mg} / \mathrm{kg}$ the results showed decrease in fentanyl and morphine consumption. Also there are no observed side effects like pruritus, nausea, vomiting, etc. except hallucination in three patients. Visual analogue score for the pain in ketamine and magnesium groups was not there at rest but there is a slight pain at $4^{\text {th }}$ and 1 sthour pain at cough respectively. Several studies indicate that Ketamine has persistent effect on central nervous system sensitization. ${ }^{[18]}$ However, we observed a decrease in morphine requirement during only upto $4 \mathrm{hrs}$ after surgery. This may be due to insufficient dose of ketamine for therapeutic plasma levels or short duration of pharmacokinetic effects of ketamine.

The results regarding intraoperative and post operative analgesic need after magnesium supplementation are contradictory. Generally there is a significant decrease in serum magnesium levels intra and post operatively in almost all surgeries. ${ }^{[19]}$ Contrastingly in a study by Koinig H, et al. showed that administration of magnesium lead to a significant reduction of intra and postoperative analgesic requirements. ${ }^{[20]}$ Similarly in the other study by Tramer MR, et al. showed that perioperative administration of magnesium sulfate was associated with smaller analgesic requirement, less discomfort, and a better quality of sleep in the postoperative period but no adverse effects and cumulative morphine consumption after 48 hrs was $30 \%$ less in magnesium treated patients. ${ }^{[21]}$

In our study administration of magnesium sulfate decreased introperative fentanyl consumption by $14 \%$ and cumulative morphine consumption for the $1^{\text {st }} 24 \mathrm{hrs}$ by $36 \%$ when compared with control group, but the difference in reduction of morphine consumption for first four post operative hours when compared to control group was not significant. This may be due to no interaction between opioids and magnesium. The cumulative consumption of morphine for the $1^{\text {st }} 24$ hours of post operative period was about $6 \%$ less than Ketamine group and 36\% less than control group. Decrease in serum magnesium levels in control and Ketamine groups intra and post operatively may explain the increase in analgesic requirements in these groups compared to morphinegroup.

When observed the heart rate, there is no significant difference in both preoperative and introperative patients in all the three groups. The mean systolic blood pressure was high in control groups of preoperative as well as 4 thand $6^{\text {th }}$ hrs of postoprative period. Similarly mean diastolic blood pressure was observed to be high in preoperative control groups. And postoperative DBP was increase at 
6thpostoperative hour. This indicates the use of adjuvant usage of ketamine and magnesium maintained a very good systolic and diastolic blood pressure. This study suggests that ketamine and magnesium sulfate drugs when administered as adjuvant therapy for the laparoscopic cholecystectomy patients helped in reduced usage of other pain management drugs.

\section{Conclusion}

In conclusion, patients those who underwent cholecystectomy surgery were not having any symptoms like nausea, vomiting, and pruritus in all the three groups. Intraoperative and postoperative pain was reduced by using lower doses of ketamine i.e. $0.5 \mathrm{mg} / \mathrm{kg}$ and magnesium sulfate i.e. $20 \mathrm{mg} / \mathrm{kg}$ as preoperative analgesic drugs. It is also observed that the ketamine effect was more efficient in comparison with magnesium by means of reducing analgesic requirement during the intraoperative period and during the first four hours of post operative period. Magnesium was succeeded in reducing the cumulative morphine consumption in first $24 \mathrm{hrs}$ of postoperative period. With the present study we can suggest that the Preoperative usage of lower doses of ketamine and magnesium sulfate (NMDA receptor blockers) was safe and reduces requirement of opioid for the major surgeries.

\section{References}

1. Christina M.Spofford, Robert W.Hurley. Preventive Analgesia. Essentials of Pain Medicine (Fourth Edition). 2018, Pages105-110.e1.

2. Lennard TW, Shenton BK, Borzotta A, Donnelly PK, White M, Gerrie LM, Proud G, Taylor RM. The influence of surgical operations on components of the human immune system. Br J Surg.1985;72(10):771-

3. Michael A.E. Ramsay. Acute postoperative pain management. Proc (Bayl Univ Med Cent). 2000 Jul; 13(3):244-247.

4. Veerabhadram Garimella, Christina Cellini. Postoperative Pain Control. Clin Colon Rectal Surg. 2013; 26(3):191-196.

5. Woolf CJ, Thompson SW. The induction and maintenance of central sensitization is dependent on $\mathrm{N}$-methyl-D-aspartic acid receptor activation; implications for the treatment of post-injury pain hypersensitivity states. Pain. 1991;44(3):293-9.

6. Lodge D, Johnson KM. Noncompetitive excitatory amino acid receptor antagonists. Trends Pharmacol Sci.1990;11(2):81-6.

7. Nalini Vadivelu, Erika Schermer, Vijay Kodumudi, Kumar Belani, Richard D Urman, Alan David Kaye. Role of ketamine for analgesia in adults and children. J Anaesthesiol Clin Pharmacol. 2016; 32(3): 298306.

8. Cromhout A. Ketamine: its use in the emergency department. Emerg Med (Fremantle). 2003;15(2):155-9.

9. Niesters M, Martini C, Dahan A. Ketamine for chronic pain: risks and benefits. Br J Clin Pharmacol.2014;77(2):357-67.

10. Dong C, Anand KJ. Developmental neurotoxicity of ketamine in pediatric clinical use. Toxicol Lett.2013;220(1):53-60.

11. Gupta K, Vohra V, Sood J. The role of magnesium as an adjuvant during general anaesthesia. Anaesthesia.2006;61(11):1058-63.

12. Sang-Hwan Do. Magnesium: a versatile drug for anesthesiologists. Korean J Anesthesiol. 2013; 65(1):4-8.

13. Ryu JH, Sohn IS, Do SH. Controlled hypotension for middle ear surgery: a comparison between remifentanil and magnesium sulphate. Br J Anaesth.2009;103(4):490-5.

14. Hyo-Seok Na, Jung-Hee Ryu, and Sang-Hwan Do. The role of magnesium in pain. Vink R, Nechifor M, editors. Adelaide (AU): University of Adelaide Press;2011.

15. Rodríguez-Rubio L, Nava E, Del Pozo JSG, Jordán J. Influence of the perioperative administration of magnesium sulfate on the total dose of anesthetics during general anesthesia. A systematic review and metaanalysis. J Clin Anesth.2017;39:129-138.

16. Dabbagh A, Elyasi H, Razavi SS, Fathi M, Rajaei S. Intravenous magnesium sulfate for post- operative pain in patients undergoing lower limb orthopedic surgery. Acta Anaesthesiol Scand. 2009;53(8):1088-91.

17. Zakine J, Samarcq D, Lorne E, Moubarak M, Montravers P, Beloucif S, Dupont H. Postoperative ketamine administration decreases morphine consumption in major abdominal surgery: a prospective, randomized, double-blind, controlled study. Anesth Analg. 2008;106(6):1856-61.

18. Sarah Lee O'Brien, Sanjog Pangarkar, Joshua Prager. The Use of Ketamine in Neuropathic Pain. Current Physical Medicine and Rehabilitation Reports. 2014, 2(2), pp128-145.

19. Zuccalà G1, Pahor M, Lattanzio F, Vagnoni S, Rodolà F, De Sole P, Cittadini A, Cocchi A, Bernabei R. Detection of arrhythmogenic cellular magnesium depletion in hip surgery patients. $\mathrm{Br} \mathrm{J}$ Anaesth.1997;79(6):776-81.

20. Koinig H1, Wallner T, Marhofer P, Andel H, Hörauf K, Mayer N. Magnesium sulfate reduces intra- and postoperative analgesic requirements. Anesth Analg.1998;87(1):206-10.

21. Tramer MR, Schneider J, Marti RA, Rifat K. Role of magnesium sulfate in postoperative analgesia. Anesthesiology.1996;84(2):340-7.

Copyright: (c) the author(s), publisher. Academia Anesthesiologica International is an Official Publication of "Society for Health Care \& Research Development". It is an open-access article distributed under the terms of the Creative Commons Attribution Non-Commercial License, which permits unrestricted non-commercial use, distribution, and reproduction in any medium, provided the original work is properly cited.

How to cite this article: Thakur N, Pula R, Raya R. Effect of Preoperative Ketamine and Magnesium Sulfate on Intra \& Postoperative Analgesia in Laparoscopic Cholecystectomy: A Comparative Randomized Controlled Study. Acad. Anesthesiol. Int. 2019;4(2):281-7.

DOI: dx.doi.org/10.21276/aan.2019.4.2.63

Source of Support: Nil, Conflict of Interest: None declared. 